\title{
Variability in chemotherapy delivery for elderly women with advanced stage ovarian cancer and its impact on survival
}

\author{
JD Wright ${ }^{1,4}$, T Doan ${ }^{2}$, R McBride ${ }^{2,3}$, JS Jacobson ${ }^{2}$ and DL Hershman*,2,3,4 \\ 'Department of Obstetrics and Gynecology, Herbert Irving Comprehensive Cancer Center, College of Physicians and Surgeons, New York, NY I0032, \\ USA; ${ }^{2}$ Department of Epidemiology, Mailman School of Public Health, Columbia University, New York, NY 10032, USA; ${ }^{3}$ Department of Medicine, \\ Herbert Irving Comprehensive Cancer Center, College of Physicians and Surgeons, New York, NY 10032, USA; ${ }^{4}$ New York Presbyterian Hospital, New \\ York, NY 10032, USA
}

\begin{abstract}
Given the survival benefits of adjuvant chemotherapy for advanced ovarian cancer (OC), we examined the associations of survival with the time interval from debulking surgery to initiation of chemotherapy and with the duration of chemotherapy. Among patients $\geqslant 65$ years with stages III/IV OC diagnosed between 199I and 2002 in the Surveillance, Epidemiology, and End Results-Medicare database, we developed regression models of predictors of the time interval from surgery to initiation of chemotherapy and of the total duration of chemotherapy. Survival was examined with Cox proportional hazards models. Among 2558 patients, 17I2 (67\%) initiated chemotherapy within 6 weeks of debulking surgery, while 846 (33\%) began treatment $>6$ weeks. Older age, black race, being unmarried, and increased comorbidities were associated with delayed initiation of chemotherapy. Delay of chemotherapy was associated with an increase in mortality (hazard ratio $(H R)=1.11 ; 95 \% \mathrm{Cl}, 1.0-1.2$ ). Among 1932 patients in the duration of treatment analysis, the $1218(63 \%)$ treated for $3-7$ months had better survival than the $714(37 \%)$ treated for $\leqslant 3$ months $(H R=0.84 ; 95 \% \mathrm{Cl}, 0.75-0.94)$. This analysis represents one of the few studies describing treatment delivery and outcome in women with advanced OC. Delayed initiation and early discontinuation of chemotherapy were common and associated with increased mortality.
\end{abstract}

British Journal of Cancer (2008) 98, I197-1203. doi:I0.1038/sj.bjc.6604298 www.bjcancer.com

Published online 18 March 2008

(c) 2008 Cancer Research UK

Keywords: ovarian cancer; chemotherapy; treatment delay; duration of chemotherapy

Over the past three decades, advances in chemotherapy, including platinum- and taxane-based regimens and intraperitoneal chemotherapy, have improved survival among women with advanced ovarian cancer (OC) (Alberts et al, 1996; Markman et al, 2001; Armstrong et al, 2006).

Failure to receive standard therapy is associated with decreased survival (Tingulstad et al, 2003). However, not all patients, especially elderly patients, are offered optimal chemotherapy. A study by our group found that although $83 \%$ of elderly patients with stage III and IV disease received some form of chemotherapy, only $52 \%$ received platinum-based therapy. Factors associated with non-platinum-based treatment included older age, nonwhite ethnicity and number of comorbid medical conditions (Sundararajan et al, 2002). Provider type and surgical volume have also been shown to influence the likelihood of receiving chemotherapy (Schrag et al, 2006).

\footnotetext{
* Correspondence: Dr D Hershman, Department of Medicine, Herbert Irving Comprehensive Cancer Center, College of Physicians and Surgeons, 161 Ft Washington Room 1068, New York, NY 10032, USA; E-mail: dlh23@columbia.edu

Received 17 December 2007; revised 14 February 2008; accepted 21 February 2008; published online 18 March 2008
}

Dose-intense treatment (higher $\mathrm{mg}$ per $\mathrm{m}^{2}$ per unit of time) has been found to improve the survival of patients with breast cancer and other cancers (Hudis et al, 1999; Citron et al, 2003). But most clinical trials among patients with OC have failed to show a survival advantage of dose-intense regimens (McGuire et al, 1995, 1996; Conte et al, 1996; Jakobsen et al, 1997; McGuire, 1997; Gore et al, 1998). For example, the Gynecologic Oncology Group (GOG) compared patients treated with eight cycles of standard dose cisplatin and cyclophosphamide to those receiving four cycles of high-dose therapy. Although response rates and survival were similar, toxicity was more common in the dose-intense group than in the standard dose group (McGuire et al, 1995).

The optimal timing of chemotherapy initiation in the postoperative period and the ideal duration of treatment (including number of cycles) have not been determined. However, in most clinical trials, patients are required to register within 6 weeks of surgery. Studies examining the time from surgery to initiation of adjuvant chemotherapy have reported varied results; however, some have suggested that prolonging the interval between surgery and the initiation of adjuvant chemotherapy adversely affects survival (Omura et al, 1989; Warwick et al, 1995; Flynn et al, 2002; Gadducci et al, 2005; Paulsen et al, 2006a; Aletti et al, 2007).

The goal of our study was to analyse the association of demographic and clinical factors with delay in initiation of chemotherapy and early termination of chemotherapy in women 
with advanced OC and to evaluate the association of those aspects of treatment with survival.

\section{MATERIALS AND METHODS}

\section{Data source}

For this analysis, we obtained data from two linked databases. The National Cancer Institute's Surveillance, Epidemiology, and End Results (SEER) cancer registry collects data on cancer patients representing $26 \%$ of the US population from five state-based and seven county-based cancer registries. The SEER database includes patient demographics; cancer organ/site, histology, stage and other clinical markers; and primary treatment. The Center for Medicare and Medicaid Services (CMS) maintains a database of patients on Medicare with diagnosis codes and procedural billing codes for their medical expenses. The SEER-Medicare linked database, initiated in 1991, has been previously described and validated (Klabunde et al, 2000; Warren et al, 2002).

\section{Patient selection criteria}

Eligible patients were those 65 years of age or older at diagnosis with a first primary epithelial OC, American Joint Cancer Committee (AJCC) stage III or IV, and diagnosed between 1 January 1991 and 31 December 2002.

Patients were included in the analysis if they received at least one cycle of chemotherapy within 12 months after surgical resection, survived for at least 7 months after initiating chemotherapy and received chemotherapy continuously for $\leqslant 7$ months. Patients who received chemotherapy for $>7$ months may have had refractory disease, which is not the focus of this study. Patients who did not receive primary, cancer-directed surgery at all or prior to receiving chemotherapy were excluded. Patients who were members of a Medicare health maintenance organization (HMO) at any time from 12 months before to 8 months after their diagnosis of OC also were excluded, because HMOs do not report claims for individual expenses to Medicare. Other exclusion criteria were gaps in Medicare Part A or B coverage during the study period, histologically unconfirmed diagnosis, non-epithelial tumour histology and tumour of low malignant potential. Among 3585 patients who underwent surgery for OC, 1021 did not receive chemotherapy within 12 months of surgery and were excluded.

For each eligible patient, we obtained data on age group at diagnosis, year of diagnosis, race/ethnicity, marital status, tumour stage (III or IV), tumour histology (serous, mucinous, endometrioid, other), comorbidity score, residence (metropolitan or nonmetropolitan), type of hospital (teaching or non-teaching) in which they were diagnosed, and socioeconomic indicators for their census tract/zip code of residence from SEER. Comorbidity data and treatment data were obtained from Medicare.

\section{Treatment delay}

The time, in weeks, from surgical resection until delivery of the first cycle of chemotherapy was calculated for each patient. Based on the inclusion criteria for GOG clinical trials, we categorised patients who initiated chemotherapy $\leqslant 6$ weeks after surgical resection as receiving timely treatment, and patients who initiated treatment $>6$ weeks after surgery as receiving delayed treatment. In addition, we categorised patients by 4-week intervals to determine the potential benefit of early initiation of treatment.

\section{Early termination of treatment}

Only women who initiated chemotherapy within 12 weeks after surgery were included in the analysis of early termination of therapy. Treatment duration was defined as the number of days between the first and last claim for chemotherapy. Subjects were categorised as receiving treatment for $\leqslant 3$ months or 3-7 months.

\section{Treatment}

We used the International Classification of Diseases, 9th revision, Clinical Modification (ICD-9-CM) codes and AMA Current Procedural Terminology Codes (CPT) to categorise surgical procedures for OC. Among patients who underwent OC-directed surgery, we identified patients who received any cytotoxic chemotherapy in a physician's office or in an outpatient hospital unit.

\section{Socioeconomic status}

An aggregate socioeconomic status (SES) score was generated from a hierarchy of income data from the 2000 Census, according to the method adapted from Nancy Krieger (Bach et al, 1999). Patients were ranked on a $1-5$ scale, with 1 as the lowest value, based on a formula that incorporated as many of the following variables as were available: median income in the census tract of residence, median income in the zip code of residence, census tract per capita income, zip code per capita income. Patients for whom all values were missing were assigned to the lowest SES category.

\section{Comorbid disease}

To assess the prevalence of comorbid disease in our cohort, we used the Charlson comorbidity index as adapted by Klabunde et al (Deyo et al, 1992; Klabunde et al, 2000, 2002). Medicare inpatient and outpatient claims were searched for ICD-9-CM diagnostic codes that indicated a history of myocardial infarction, congestive heart failure, peripheral vascular disease, cerebrovascular disease, dementia, chronic pulmonary disease, connective tissue disease, mild-to-severe liver disease, diabetes with or without end-organ damage, hemiplegia, moderate-to-severe renal disease, or acquired immunodeficiency syndrome in the Medicare files from 12 months before to 1 month after the diagnosis of cancer. Each condition was weighted, and patients were assigned a score based on the Klabunde-Charlson index (Klabunde et al, 2000, 2002).

\section{Survival}

Survival was calculated as the number of months from the cancer diagnosis date to the Medicare date of death. Ovarian-cancerspecific survival was defined as the number of months from the cancer diagnosis to date of death from OC. Patients who survived past the end of follow-up (31 December 2003) were censored and contributed the time from their diagnosis date to the end of followup to the analyses of overall survival.

\section{Statistical analysis}

The $\chi^{2}$ test was used to compare the frequency distributions of categorical variables. All hypothesis tests were two-sided. In a logistic regression analysis, we modelled the predictors of delayed treatment. In Cox proportional hazards analyses, we modelled the overall mortality hazard ratios (HRs) of patients who received delayed treatment compared to other patients, controlling for the other predictor variables. We also generated adjusted KaplanMeier curves of overall survival by delayed $v s$ timely start of chemotherapy and for termination in $\leqslant 3 v s>3$ months.

\section{RESULTS}

We identified 6047 individuals with stages III-IV epithelial OC from the SEER-Medicare database. A total of 3585 women underwent OC-directed surgery. Among these women, 2558 
Table I Univariate associations between weeks to initiation of chemotherapy and demographic and clinical variables

\begin{tabular}{|c|c|c|c|c|c|c|c|}
\hline \multirow[b]{2}{*}{ Months to chemotherapy } & \multicolumn{2}{|c|}{$\leqslant 6$} & \multicolumn{2}{|c|}{6} & \multicolumn{2}{|c|}{ Total } & \multirow[b]{2}{*}{$P$-value } \\
\hline & $\mathbf{N}$ & $\%$ & $\mathbf{N}$ & $\%$ & $\mathbf{N}$ & $\%$ & \\
\hline & 1712 & (67) & 846 & (33) & 2558 & $(100)$ & \\
\hline \multicolumn{8}{|l|}{ Age at diagnosis } \\
\hline $65-69$ & 475 & (28) & 203 & (24) & 678 & (27) & \\
\hline $70-74$ & 593 & (35) & 259 & (3I) & 852 & (33) & \\
\hline $75-79$ & 429 & (25) & 242 & (29) & 671 & (26) & \\
\hline $80+$ & 215 & (13) & 142 & (17) & 357 & (14) & 0.0002 \\
\hline \multicolumn{8}{|l|}{ Race } \\
\hline White & 1598 & (94) & 756 & (89) & 2354 & (92) & \\
\hline Black & 42 & (2) & 44 & (5) & 86 & (3) & \\
\hline Other & 72 & (4) & 46 & (5) & 118 & (5) & 0.0004 \\
\hline \multicolumn{8}{|l|}{ Live in metropolitan location } \\
\hline No & 159 & (9) & 67 & (8) & 226 & (9) & \\
\hline Yes & 1553 & (91) & 779 & $(92)$ & 2332 & $(9 \mid)$ & 0.25 \\
\hline \multicolumn{8}{|l|}{ Marital status } \\
\hline No & 752 & (44) & 426 & $(50)$ & 1178 & (46) & \\
\hline Yes & 916 & (54) & 395 & (47) & 1311 & $(51)$ & \\
\hline Unknown & 44 & (3) & 25 & (3) & 69 & (3) & 0.005 \\
\hline \multicolumn{8}{|l|}{ Teaching hospital } \\
\hline No & 302 & (।8) & 166 & (20) & 468 & (।8) & \\
\hline Yes & 1410 & $(82)$ & 680 & $(80)$ & 2090 & (82) & 0.22 \\
\hline \multicolumn{8}{|l|}{ Histology } \\
\hline Serous & 1066 & $(62)$ & 508 & $(60)$ & 1574 & (62) & \\
\hline Mucinous & 58 & (3) & 40 & (5) & 98 & (4) & \\
\hline Endometrioid & 150 & (9) & 59 & (7) & 209 & (8) & \\
\hline Other & 438 & (26) & 239 & $(28)$ & 677 & (26) & 0.077 \\
\hline \multicolumn{8}{|l|}{ Stage } \\
\hline III & 1065 & (62) & 530 & (63) & 1595 & (62) & \\
\hline IV & 647 & (38) & 316 & (37) & 963 & (38) & 0.83 \\
\hline \multicolumn{8}{|l|}{ No. of comorbid conditions } \\
\hline 0 & 894 & (52) & 403 & (48) & 1297 & (5।) & \\
\hline 1 & 475 & (28) & 241 & (28) & 716 & (28) & \\
\hline$\geqslant 2$ & 343 & $(20)$ & 202 & $(24)$ & 545 & $(21)$ & 0.03 \\
\hline \multicolumn{8}{|l|}{ SES } \\
\hline Lowest quintile & 318 & (19) & 156 & (।8) & 474 & (19) & \\
\hline Second quintile & 324 & (19) & 161 & (19) & 485 & (19) & \\
\hline Third quintile & 343 & (20) & 172 & (20) & 515 & (20) & \\
\hline Fourth quintile & 338 & (20) & 174 & $(21)$ & 512 & (20) & \\
\hline Fifth quintile & 389 & (23) & 183 & (22) & 572 & (22) & 0.97 \\
\hline
\end{tabular}

(71\%) received at least one cycle of chemotherapy. Table 1 shows their demographic characteristics.

\section{Treatment delay}

Among the 2558 patients who received chemotherapy, 1712 (67\%) began treatment within 6 weeks of surgery, while $846(33 \%)$ initiated chemotherapy $>6$ weeks after surgery. The median time to the initiation of chemotherapy was 5 weeks after surgery. In univariate analysis, advanced age, black race, being unmarried and an increased number of comorbid conditions were associated with delayed treatment; living in a metropolitan area, treatment at a teaching hospital, advanced stage, histology, SES and year of diagnosis were not associated with delayed treatment (Table 1). In a logistic regression model, advanced age, black race and marital status were associated with delayed initiation of chemotherapy
Table 2 Association of demographic and clinical characteristics with initiation of chemotherapy $>6$ weeks after surgery and overall mortality hazard ratios in patients with ovarian cancer by time to initiation of chemotherapy

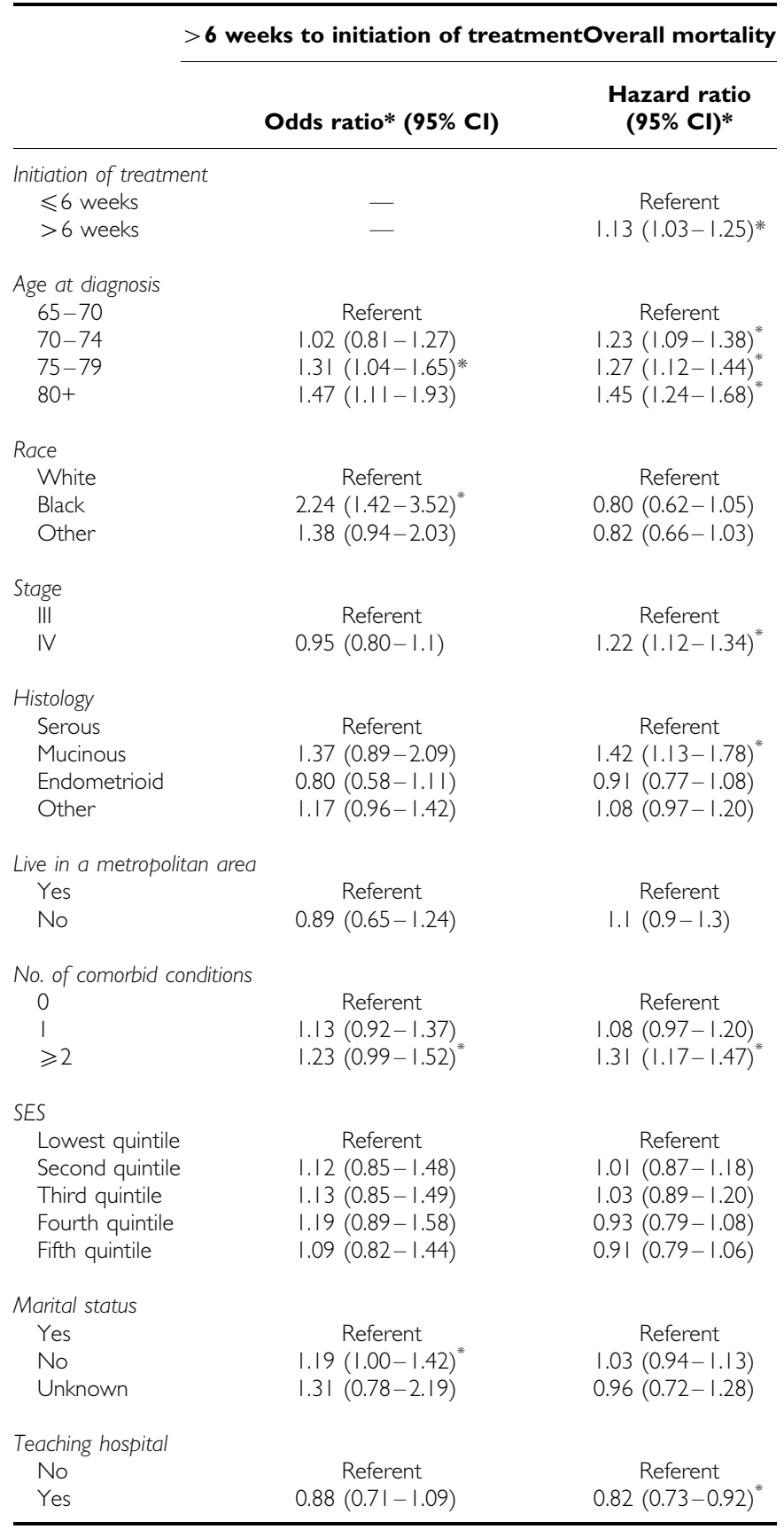

All variables controlled for each other, and year of diagnosis. $* P<0.01$.

(Table 2). Black patients were more than twice as likely as white patients to delay initiation of chemotherapy $(P=0.0007)$.

In a Cox proportional hazards regression model, treatment delay was associated with a $13 \%$ increase in overall mortality $(\mathrm{HR}=1.13$; 95\% CI, 1.03-1.25) (Table 2). Advanced age at diagnosis, stage IV disease, mucinous histology and increasing medical comorbidities were also associated with an increased risk of death. Treatment at a teaching hospital was associated with a lower mortality. 
The median survival for women who initiated treatment within 6 weeks was 34 months compared to 28 months for patients who began therapy more than 6 weeks after surgery. Kaplan-Meier analysis demonstrated that women who initiated treatment $>6$ weeks after had poorer overall $(P<0.0001)$ and OC-specific $(P=0.009)$ survival than women who did not delay treatment (Figure 1). However, initiating therapy $<4$ weeks postoperatively provided no survival benefit from doing so at 4-8 weeks $(P=0.27)$.

\section{Early termination of treatment}

Among the 1932 patients who initiated therapy within 12 weeks after surgery (Table 3 ), the median duration of therapy was 3.5 months or $\sim 15$ weeks, consistent with our assumption that if standard treatment with six cycles were administered every 3 weeks, it would take about 15 weeks from initiation to completion of therapy. A total of 714 patients $(37 \%)$ were treated for $\leqslant 3$ months and 1218 (63\%) for 3-7 months. In univariate analysis, race, type of hospital and number of medical comorbidities were associated with duration of treatment (Table 3). In a logistic regression model treatment at a teaching hospital was associated with receiving 3-7 months of therapy (Table 4).

In a Cox proportional hazards regression model, patients treated for 3-7 months had $16 \%$ lower mortality than patients treated for $\leqslant 3$ months ( $\mathrm{HR}=0.84 ; 95 \% \mathrm{CI}, 0.75-0.94)$ (Table 4$)$. The median survival was 38 months for those treated for 3-7 months compared to 33 months for women treated for $<3$ months. Figure 2 displays the Kaplan-Meier plots of survival as a function of treatment duration. Treatment for $\leqslant 3$ months was associated with poorer overall $(P<0.0001)$ and cancer-specific $(P<0.0001)$ survival than longer treatment.

\section{DISCUSSION}

Our findings demonstrate that among women with advanced OC who receive chemotherapy, substantial variability exists in the delivery of this treatment. Women who initiated therapy more than 6 weeks after surgery and patients who received an abbreviated course of treatment for less than 3 months were more likely to die even after adjustment for other known prognostic factors. Although waiting longer than 6 weeks to initiate therapy was associated with poorer survival, starting within 4 weeks after surgery was not associated with better survival.

The timing of initiation of adjuvant chemotherapy and survival has been studied in a variety of settings, with varied results. Among patients with lymph node-positive, oestrogen receptor-

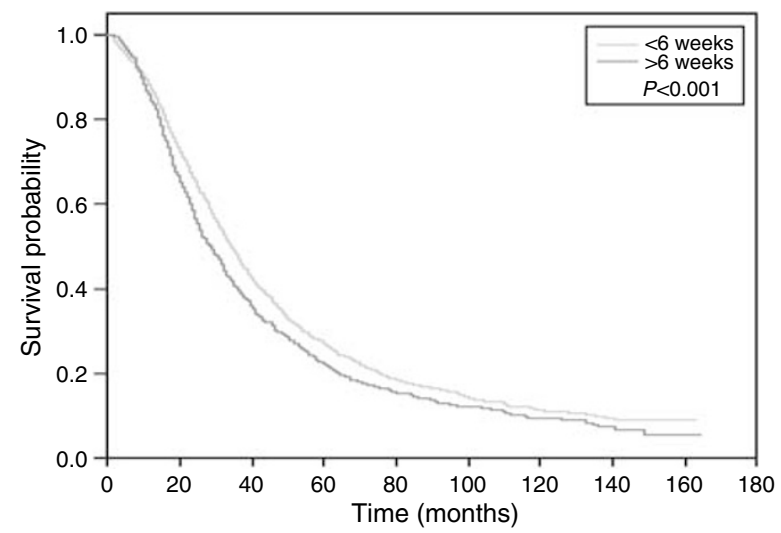

Figure I Kaplan-Meier curve for duration interval from surgery to initiation of therapy. negative breast tumours, initiation of chemotherapy within 4 weeks was associated with improved survival (Colleoni et al, 2000). Elderly patients with early-stage breast cancer appeared to derive no benefit from early initiation of chemotherapy, but long treatment initiation delays were associated with increased mortality (Hershman et al, 2006b). Other adjuvant breast cancer trials have also failed to detect a benefit from early initiation of therapy (Shannon et al, 2003; Cold et al, 2005). Our group recently reported the effect of treatment delay in patients with stage III colon cancer. In a multivariate analysis, delaying initiation of treatment for over 3 months was associated with a $50 \%$ increase in colon cancer-specific mortality (Hershman et al, 2006a).

A theoretical basis for early administration of cytotoxic agents has been demonstrated in several preclinical models. In a mouse mammary tumour model, removal of the primary lesions resulted in increased tumour proliferation and, therefore, more

Table 3 Univariate association between length of chemotherapy treatment (months) and demographic and clinical variables

\begin{tabular}{|c|c|c|c|c|c|c|c|}
\hline \multirow[b]{2}{*}{ Months of chemotherapy } & \multicolumn{2}{|c|}{$\leqslant 3$ months } & \multicolumn{2}{|c|}{ 3-7 months } & \multicolumn{2}{|c|}{ Total } & \multirow[b]{2}{*}{$P$-value } \\
\hline & $N$ & $\%$ & $N$ & $\%$ & $N$ & $\%$ & \\
\hline & 714 & (37) & 1218 & $(63)$ & 1932 & $(100)$ & \\
\hline \multicolumn{8}{|l|}{ Age at diagnosis } \\
\hline $65-69$ & 202 & (28) & 325 & (27) & 527 & (27) & \\
\hline $70-74$ & 218 & $(31)$ & 428 & (35) & 646 & (33) & \\
\hline $75-79$ & 190 & (27) & 309 & (25) & 499 & (26) & \\
\hline $80+$ & 104 & (15) & 156 & $(13)$ & 260 & $(13)$ & 0.20 \\
\hline \multicolumn{8}{|l|}{ Race } \\
\hline White & 648 & $(91)$ & 1141 & (94) & 1789 & (93) & \\
\hline Black & 29 & (4) & 26 & (2) & 55 & (3) & \\
\hline Other & 37 & (5) & 51 & $(4)$ & 88 & (5) & 0.03 \\
\hline \multicolumn{8}{|l|}{ Live in metropolitan location } \\
\hline No & 50 & (7) & 112 & (9) & 162 & (8) & \\
\hline Yes & 664 & $(93)$ & 1106 & $(91)$ & 1770 & (92) & 0.09 \\
\hline \multicolumn{8}{|l|}{ Marital status } \\
\hline No & 341 & $(48)$ & 531 & (44) & 872 & (45) & \\
\hline Yes & 350 & (49) & 652 & $(54)$ & 1002 & (52) & \\
\hline Unknown & 23 & (3) & 35 & (3) & 58 & (3) & 0.16 \\
\hline \multicolumn{8}{|l|}{ Teaching hospital } \\
\hline No & 106 & $(15)$ & 229 & $(19)$ & 335 & $(17)$ & \\
\hline Yes & 608 & (85) & 989 & $(81)$ & 1597 & (83) & 0.03 \\
\hline \multicolumn{8}{|l|}{ Histology } \\
\hline Serous & 449 & $(63)$ & 776 & (64) & 1225 & (63) & \\
\hline Mucinous & 13 & (2) & 35 & (3) & 48 & (2) & \\
\hline Endometrioid & 60 & (8) & 97 & (8) & 157 & (8) & \\
\hline Other & 192 & $(27)$ & 310 & $(25)$ & 502 & (26) & 0.47 \\
\hline \multicolumn{8}{|l|}{ Stage } \\
\hline III & 447 & (63) & 775 & (64) & 1222 & (63) & \\
\hline IV & 267 & (37) & 443 & (36) & 710 & (37) & 0.65 \\
\hline \multicolumn{8}{|l|}{ No. of comorbid conditions } \\
\hline 0 & 357 & $(50)$ & 646 & (53) & 1003 & (52) & \\
\hline 1 & 198 & (28) & 362 & (30) & 560 & (29) & \\
\hline$\geqslant 2$ & 159 & (22) & 210 & $(17)$ & 369 & (19) & 0.02 \\
\hline \multicolumn{8}{|l|}{ SES } \\
\hline Lowest quintile & 131 & $(18)$ & 208 & $(17)$ & 339 & (18) & \\
\hline Second quintile & 137 & (19) & 231 & (19) & 368 & (19) & \\
\hline Third quintile & 154 & (22) & 239 & (20) & 393 & (20) & \\
\hline Fourth quintile & 153 & $(21)$ & 246 & (20) & 399 & (2I) & \\
\hline Fifth quintile & 139 & (19) & 294 & (24) & 433 & (22) & 0.20 \\
\hline
\end{tabular}


Table 4 Association of demographic and clinical characteristics with duration of chemotherapy $\leqslant 3$ months and mortality hazard ratios in patients with ovarian cancer by duration of chemotherapy

\begin{tabular}{|c|c|c|}
\hline & $\leqslant \mathbf{3}$ months treatment & Overall mortality \\
\hline & Odds ratio* $(95 \% \mathrm{Cl})$ & Hazard ratio $(95 \% \mathrm{Cl}) *$ \\
\hline \multicolumn{3}{|l|}{ Length of treatment } \\
\hline$<3$ months & - & Referent \\
\hline $3-7$ months & - & $0.84(0.75-0.94)^{*}$ \\
\hline \multicolumn{3}{|l|}{ Age at diagnosis } \\
\hline $65-70$ & Referent & Referent \\
\hline $70-74$ & $1.23(0.96-1.57)$ & $1.29(1.12-1.48) *$ \\
\hline $75-79$ & $1.02(0.79-1.32)$ & $1.29(1.11-1.49)^{*}$ \\
\hline $80+$ & $0.96(0.70-1.32)$ & $1.49(1.25-1.79)^{*}$ \\
\hline \multicolumn{3}{|l|}{ Race } \\
\hline White & Referent & Referent \\
\hline Black & $0.60(0.34-1.05)$ & $0.83(0.59-1.17)$ \\
\hline Hispanic & $2.30(0.72-7.28)$ & $1.24(0.65-2.36)$ \\
\hline Other & $0.69(0.43-1.13)$ & $0.89(0.66-1.20)$ \\
\hline \multicolumn{3}{|l|}{ Stage } \\
\hline III & Referent & Referent \\
\hline IV & $0.97(0.80-1.18)$ & $1.26(1.13-1.40)^{*}$ \\
\hline \multicolumn{3}{|l|}{ Histology } \\
\hline Serous & Referent & Referent \\
\hline Mucinous & ।.7| (0.89-3.32) & $0.95(0.67-1.44)$ \\
\hline Endometrioid & $0.95(0.67-1.35)$ & $0.80(0.65-0.98)$ \\
\hline Other & $0.92(0.74-1.14)$ & $1.01(0.89-1.15)$ \\
\hline \multicolumn{3}{|c|}{ Live in a metropolitan area } \\
\hline Yes & Referent & Referent \\
\hline No & $1.40(0.96-2.04)$ & $1.07(0.86-1.32)$ \\
\hline \multicolumn{3}{|c|}{ No. of comorbid conditions } \\
\hline 0 & Referent & Referent \\
\hline I & $1.05(0.84-1.30)$ & $1.12(0.99-1.27)$ \\
\hline$\geqslant 2$ & $0.78(0.61-1.00)$ & $1.19(1.03-1.36)^{*}$ \\
\hline \multicolumn{3}{|l|}{ SES } \\
\hline Lowest quintile & Referent & Referent \\
\hline Second quintile & $1.08(0.79-1.47)$ & $1.04(0.87-1.24)$ \\
\hline Third quintile & $1.02(0.74-1.40)$ & $1.17(0.98-1.40)$ \\
\hline Fourth quintile & $1.05(0.76-1.44)$ & $0.94(0.78-1.13)$ \\
\hline Fifth quintile & $1.36(0.99-1.87)$ & $0.93(0.77-1.11)$ \\
\hline \multicolumn{3}{|l|}{ Marital status } \\
\hline Yes & Referent & Referent \\
\hline No & $0.88(0.73-1.07)$ & $1.10(0.98-1.22)$ \\
\hline Unknown & $0.83(0.48-1.43)$ & $1.12(0.81-1.55)$ \\
\hline \multicolumn{3}{|l|}{ Teaching hospital } \\
\hline No & Referent & Referent \\
\hline Yes & $0.75(0.58-0.97)$ & $0.83(0.73-0.96)^{*}$ \\
\hline
\end{tabular}

All variables controlled for each other and year of diagnosis. $* P<0.01$.

susceptibility to cytotoxic chemotherapeutic agents. In these studies, early perioperative initiation of chemotherapy resulted in better tumour control than delayed therapy (Fisher et al, 1983; Bell et al, 1988).

A prospective GOG trial of adjuvant cisplatin and cyclophosphamide with or without doxorubicin examined the effect of delay in the initiation of treatment and outcome for 349 patients with stage III OC. The investigators categorised patients by week of initiation and found that women who began therapy at week 6 had worse survival than those treated earlier (Omura et al, 1989). In a multicentre retrospective Italian report as well as a single

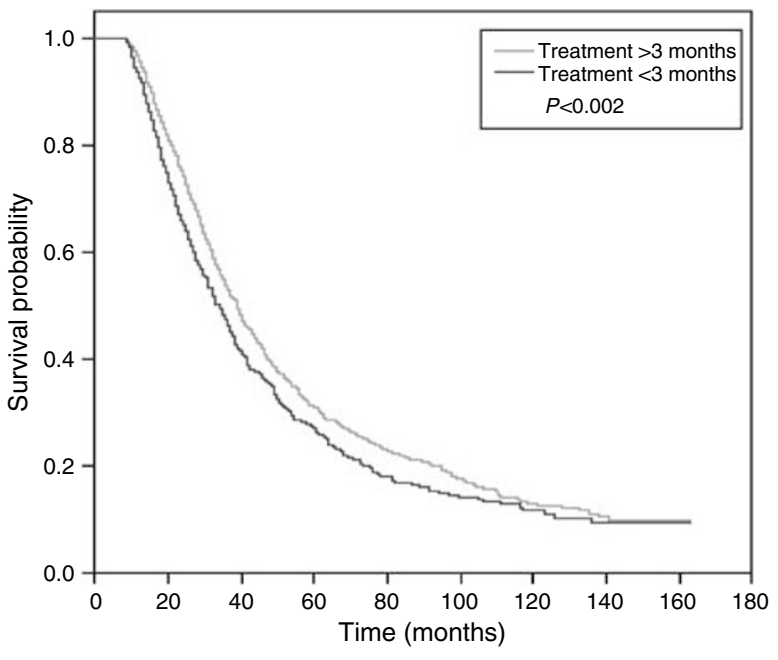

Figure 2 Kaplan-Meier curve for duration chemotherapy.

institution study from the United States, timing to initiation of treatment had no effect on survival (Gadducci et al, 2005; Aletti et al, 2007). In a separate study of 472 patients, Flynn et al (2002) found that women who started chemotherapy within 3 weeks after surgery had a shorter progression-free interval than women who started later. However, the early treatment group had a significantly higher percentage of patients with large volume residual tumours.

Our study differs from previous reports in several respects. We compared patients who initiated treatment 6 weeks or earlier after surgery with women who began treatment later. The majority of previous studies divided patients by much shorter time intervals. Patients in the GOG trial were all treated within 6 weeks and stratified by weekly intervals (Omura et al, 1989). Similarly, the majority of patients in the other reports were treated relatively early (Flynn et al, 2002; Gadducci et al, 2005; Aletti et al, 2007). Aletti et al (2007) and the Multicenter Italian Study Group divided patients into quartiles, the last quartile consisting of patients treated > 34 days after surgery (Omura et al, 1989; Gadducci et al, 2005). These data suggest that very early treatment may be of limited clinical benefit but that prolonged delays in treatment initiation may have a deleterious effect on survival. Half of our elderly subjects were treated 5 weeks or more after surgery. The relative contributions of patient and physician preferences, performance status and duration of recovery from surgery to delay are unknown.

We found that women treated with chemotherapy for a total duration of $<3$ months had a $16 \%$ higher risk of dying than women treated longer. Similar findings have been reported in both adjuvant colon cancer and breast cancer treatment (Tingulstad et al, 2003; Hershman et al, 2005). Previous reports have found that patients treated at teaching hospitals were more likely than those at non-teaching hospitals to receive a full six cycles of therapy (Tingulstad et al, 2003; Paulsen et al, 2006b). In a patterns of care study, Paulsen et al (2006b) demonstrated that $43 \%$ of patients at non-teaching hospitals but only $16 \%$ of patients at teaching hospitals received $<6$ courses of therapy. Notably, only $72 \%$ of women at non-teaching hospitals received some form of chemotherapy. In our cohort, $32 \%$ of patients at non-teaching hospitals compared to $38 \%$ at teaching hospitals received $<3$ months of therapy. While statistically significant, the difference was quite small.

This study is one of the first to examine age and racial differences in the quality of chemotherapy delivery in women with OC. Advancing age was associated with a progressively greater risk 
of delay in initiation of chemotherapy. Previous work has suggested that elderly OC patients are less likely to receive chemotherapy than younger patients and that those who do are often treated with less-aggressive regimens (Bruchim et al, 2002; Efstathiou et al, 2007). A recent study of breast cancer patients suggested that black patients and elderly patients were more likely to receive nonstandard treatment regimen (Griggs et al, 2007). Similarly, in our series, black patients were more likely to experience a delay in starting chemotherapy. Previous univariate analysis of SEER data suggested that black patients were less likely to receive guideline-based chemotherapy (Harlan et al, 2003).

Treatment quality is influenced by physician-related factors. Several studies have demonstrated superior outcomes for women treated by surgical specialists and high-volume surgeons (Junor et al, 1999; Carney et al, 2002; Elit et al, 2002; Earle et al, 2006; Goff et al, 2006, 2007; Paulsen et al, 2006b; Vernooij et al, 2007). In an analysis of over 3000 patients, those operated on by gynaecologic oncologists were more likely to undergo surgical cytoreduction and had improved outcomes (Earle et al, 2006). Likewise, patients who were operated on at high-volume facilities and teaching hospitals are more likely to undergo comprehensive surgical staging and cytoreduction, and have better survival than those treated at smaller and non-teaching hospitals (Tingulstad et al, 2003; Paulsen et al, 2006b; Vernooij et al, 2007). However, many patients with OC do not receive care from surgical specialists or at large volume facilities (Carney et al, 2002; Bristow et al, 2004).

Although the patients in the SEER-Medicare database are representative of elderly patients treated in the United States, the database has a number of limitations. It does not include patients under the age of 65 years. It does not include data on important prognostic factors, such as the volume of residual tumour at the initiation of chemotherapy; the actual doses delivered (we used duration of therapy as a surrogate for dose intensity); patient and physician preferences, which are critically important to both the initiation and continuation of chemotherapy; and performance status. Although we used age and medical comorbidities as surrogates, these variables are unable to compensate fully for the lack of performance status information.

Our findings indicate that delayed treatment initiation and early chemotherapy discontinuation were common in elderly women with OC, and that these variations in treatment delivery are associated with survival. Although early initiation of chemotherapy appears to confer little benefit, prolonged delays in beginning treatment and early discontinuation of treatment are associated with poor outcomes. Prospective studies of factors that influence the quality of care in women with OC are needed, but until such studies are completed, efforts should be made to facilitate prompt initiation and full completion of adjuvant chemotherapy.

\section{ACKNOWLEDGEMENTS}

This study used the linked SEER-Medicare database. The interpretation and reporting of these data are the sole responsibility of the authors. We acknowledge the efforts of the Applied Research Branch, Division of Cancer Prevention and Population Science, NCI; the Office of Information Services, and the Office of Strategic Planning, HCFA; Information Management Services (IMS) Inc.; and the Surveillance, Epidemiology, and End Results (SEER) Program tumor registries in the creation of the SEERMedicare database. Dr Hershman is the recipient of an ASCO ACRA Award. Russell McBride is the recipient of an NCI R25 (CA94061), and a T32 (ULI RR024156) from the NIH-NCRR. Dr Neugut is the recipient of a grant from the American Cancer Society (RSGT-01-024-04-CPHPS).

\section{REFERENCES}

Alberts DS, Liu PY, Hannigan EV, O’Toole R, Williams SD, Young JA, Franklin EW, Clarke-Pearson DL, Malviya VK, DuBeshter B (1996) Intraperitoneal cisplatin plus intravenous cyclophosphamide $v s$ intravenous cisplatin plus intravenous cyclophosphamide for stage III ovarian cancer. N Engl J Med 335: $1950-1955$

Aletti GD, Long HJ, Podratz KC, Cliby WA (2007) Is time to chemotherapy a determinant of prognosis in advanced-stage ovarian cancer? Gynecol Oncol 104: 212 - 216

Armstrong DK, Bundy B, Wenzel L, Huang HQ, Baergen R, Lele S, Copeland LJ, Walker JL, Burger RA (2006) Intraperitoneal cisplatin and paclitaxel in ovarian cancer. $N$ Engl J Med 354: 34-43

Bach PB, Cramer LD, Warren JL, Begg CB (1999) Racial differences in the treatment of early-stage lung cancer. N Engl J Med 341: 1198-1205

Bell RS, Roth YF, Gebhardt MC, Bell DF, Rosenberg AE, Mankin HJ, Suit HD (1988) Timing of chemotherapy and surgery in a murine osteosarcoma model. Cancer Res 48: 5533-5538

Bristow RE, Zahurak ML, del Carmen MG, Gordon TA, Fox HE, Trimble EL, Montz FJ (2004) Ovarian cancer surgery in Maryland: volume-based access to care. Gynecol Oncol 93: $353-360$

Bruchim I, Altaras M, Fishman A (2002) Age contrasts in clinical characteristics and pattern of care in patients with epithelial ovarian cancer. Gynecol Oncol 86: 274-278

Carney ME, Lancaster JM, Ford C, Tsodikov A, Wiggins CL (2002) A population-based study of patterns of care for ovarian cancer: who is seen by a gynecologic oncologist and who is not? Gynecol Oncol 84: 36-42

Citron ML, Berry DA, Cirrincione C, Hudis C, Winer EP, Gradishar WJ, Davidson NE, Martino S, Livingston R, Ingle JN, Perez EA, Carpenter J, Hurd D, Holland JF, Smith BL, Sartor CI, Leung EH, Abrams J, Schilsky RL, Muss HB, Norton L (2003) Randomized trial of dose-dense vs conventionally scheduled and sequential vs concurrent combination chemotherapy as postoperative adjuvant treatment of node-positive primary breast cancer: first report of Intergroup Trial C9741/Cancer and Leukemia Group B Trial 9741. J Clin Oncol 21: 1431-1439
Cold S, During M, Ewertz M, Knoop A, Moller S (2005) Does timing of adjuvant chemotherapy influence the prognosis after early breast cancer? Results of the Danish Breast Cancer Cooperative Group (DBCG). $\mathrm{Br} J$ Cancer 93: 627-632

Colleoni M, Bonetti M, Coates AS, Castiglione-Gertsch M, Gelber RD, Price K, Rudenstam CM, Lindtner J, Collins J, Thurlimann B, Holmberg S, Veronesi A, Marini G, Goldhirsch A (2000) Early start of adjuvant chemotherapy may improve treatment outcome for premenopausal breast cancer patients with tumors not expressing estrogen receptors. The International Breast Cancer Study Group. J Clin Oncol 18: $584-590$

Conte PF, Bruzzone M, Carnino F, Gadducci A, Algeri R, Bellini A, Boccardo F, Brunetti I, Catsafados E, Chiara S, Foglia G, Gallo L, Iskra L, Mammoliti S, Parodi G, Ragni N, Rosso R, Rugiati S, Rubagotti A (1996) High-dose $v s$ low-dose cisplatin in combination with cyclophosphamide and epidoxorubicin in suboptimal ovarian cancer: a randomized study of the Gruppo Oncologico Nord-Ovest. J Clin Oncol 14: $351-356$

Deyo RA, Cherkin DC, Ciol MA (1992) Adapting a clinical comorbidity index for use with ICD-9-CM administrative databases. J Clin Epidemiol 45: $613-619$

Earle CC, Schrag D, Neville BA, Yabroff KR, Topor M, Fahey A, Trimble EL, Bodurka DC, Bristow RE, Carney M, Warren JL (2006) Effect of surgeon specialty on processes of care and outcomes for ovarian cancer patients. J Natl Cancer Inst 98: $172-180$

Efstathiou E, Dimopoulos MA, Bozas G, Kastritis E, Moulopoulos LA, Rodolakis A, Vlahos G, Gika D, Papadimitriou C, Bamias A (2007) Advanced epithelial ovarian cancer in the elderly: chemotherapy tolerance and outcome. Anticancer Res 27: 611-617

Elit L, Bondy SJ, Paszat L, Przybysz R, Levine M (2002) Outcomes in surgery for ovarian cancer. Gynecol Oncol 87: 260-267

Fisher B, Gunduz N, Saffer EA (1983) Influence of the interval between primary tumor removal and chemotherapy on kinetics and growth of metastases. Cancer Res 43: 1488-1492 
Flynn PM, Paul J, Cruickshank DJ (2002) Does the interval from primary surgery to chemotherapy influence progression-free survival in ovarian cancer? Gynecol Oncol 86: $354-357$

Gadducci A, Sartori E, Landoni F, Zola P, Maggino T, Maggioni A, Cosio S, Frassi E, LaPresa MT, Fuso L, Cristofani R (2005) Relationship between time interval from primary surgery to the start of taxane- plus platinumbased chemotherapy and clinical outcome of patients with advanced epithelial ovarian cancer: results of a multicenter retrospective Italian study. J Clin Oncol 23: $751-758$

Goff BA, Matthews BJ, Larson EH, Andrilla CH, Wynn M, Lishner DM, Baldwin LM (2007) Predictors of comprehensive surgical treatment in patients with ovarian cancer. Cancer 109: $2031-2042$

Goff BA, Matthews BJ, Wynn M, Muntz HG, Lishner DM, Baldwin LM (2006) Ovarian cancer: patterns of surgical care across the United States. Gynecol Oncol 103: 383-390

Gore M, Mainwaring P, A'Hern R, MacFarlane V, Slevin M, Harper P, Osborne R, Mansi J, Blake P, Wiltshaw E, Shepherd J (1998) Randomized trial of dose-intensity with single-agent carboplatin in patients with epithelial ovarian cancer. London Gynaecological Oncology Group. J Clin Oncol 16: $2426-2434$

Griggs JJ, Culakova E, Sorbero ME, Poniewierski MS, Wolff DA, Crawford J, Dale DC, Lyman GH (2007) Social and racial differences in selection of breast cancer adjuvant chemotherapy regimens. J Clin Oncol 25: $2522-2527$

Harlan LC, Clegg LX, Trimble EL (2003) Trends in surgery and chemotherapy for women diagnosed with ovarian cancer in the United States. J Clin Oncol 21: $3488-3494$

Hershman D, Hall MJ, Wang X, Jacobson JS, McBride R, Grann VR, Neugut AI (2006a) Timing of adjuvant chemotherapy initiation after surgery for stage III colon cancer. Cancer 107: 2581 - 2588

Hershman D, McBride R, Jacobson JS, Lamerato L, Roberts K, Grann VR, Neugut AI (2005) Racial disparities in treatment and survival among women with early-stage breast cancer. J Clin Oncol 23: 6639-6646

Hershman DL, Wang X, McBride R, Jacobson JS, Grann VR, Neugut AI (2006b) Delay of adjuvant chemotherapy initiation following breast cancer surgery among elderly women. Breast Cancer Res Treat 99: $313-321$

Hudis C, Fornier M, Riccio L, Lebwohl D, Crown J, Gilewski T, Surbone A, Currie V, Seidman A, Reichman B, Moynahan M, Raptis G, Sklarin N, Theodoulou M, Weiselberg L, Salvaggio R, Panageas KS, Yao TJ, Norton $\mathrm{L}$ (1999) 5-year results of dose-intensive sequential adjuvant chemotherapy for women with high-risk node-positive breast cancer: a phase II study. J Clin Oncol 17: 1118

Jakobsen A, Bertelsen K, Andersen JE, Havsteen H, Jakobsen P, Moeller KA, Nielsen K, Sandberg E, Stroeyer I (1997) Dose-effect study of carboplatin in ovarian cancer: a Danish Ovarian Cancer Group study. J Clin Oncol 15: $193-198$

Junor EJ, Hole DJ, McNulty L, Mason M, Young J (1999) Specialist gynaecologists and survival outcome in ovarian cancer: a Scottish national study of 1866 patients. Br J Obstet Gynaecol 106: $1130-1136$

Klabunde CN, Potosky AL, Legler JM, Warren JL (2000) Development of a comorbidity index using physician claims data. J Clin Epidemiol 53: $1258-1267$
Klabunde CN, Warren JL, Legler JM (2002) Assessing comorbidity using claims data: an overview. Med Care 40, IV- 26-35

Markman M, Bundy BN, Alberts DS, Fowler JM, Clark-Pearson DL, Carson LF, Wadler S, Sickel J (2001) Phase III trial of standard-dose intravenous cisplatin plus paclitaxel $v s$ moderately high-dose carboplatin followed by intravenous paclitaxel and intraperitoneal cisplatin in small-volume stage III ovarian carcinoma: an intergroup study of the Gynecologic Oncology Group, Southwestern Oncology Group, and Eastern Cooperative Oncology Group. J Clin Oncol 19: $1001-1007$

McGuire WP, Hoskins WJ, Brady MF, Homesley HD, Creasman WT, Berman ML, Ball H, Berek JS, Woodward J (1995) Assessment of doseintensive therapy in suboptimally debulked ovarian cancer: a Gynecologic Oncology Group study. J Clin Oncol 13: 1589-1599

McGuire WP, Hoskins WJ, Brady MF, Kucera PR, Partridge EE, Look KY, Clarke-Pearson DL, Davidson M (1996) Cyclophosphamide and cisplatin compared with paclitaxel and cisplatin in patients with stage III and stage IV ovarian cancer. $N$ Engl J Med 334: 1-6

McGuire WP (1997) How many more nails to seal the coffin of dose intensity? Ann Oncol 8: 311-313

Omura GA, Bundy BN, Berek JS, Curry S, Delgado G, Mortel R (1989) Randomized trial of cyclophosphamide plus cisplatin with or without doxorubicin in ovarian carcinoma: a Gynecologic Oncology Group Study. J Clin Oncol 7: 457-465

Paulsen T, Kaern J, Kjaerheim K, Haldorsen T, Trope C (2006a) Influence of interval between primary surgery and chemotherapy on short-term survival of patients with advanced ovarian, tubal or peritoneal cancer. Gynecol Oncol 102: $447-452$

Paulsen T, Kjaerheim K, Kaern J, Tretli S, Trope C (2006b) Improved shortterm survival for advanced ovarian, tubal, and peritoneal cancer patients operated at teaching hospitals. Int J Gynecol Cancer 16(Suppl 1): 11-17

Schrag D, Earle C, Xu F, Panageas KS, Yabroff KR, Bristow RE, Trimble EL, Warren JL (2006) Associations between hospital and surgeon procedure volumes and patient outcomes after ovarian cancer resection. J Natl Cancer Inst 98: $163-171$

Shannon C, Ashley S, Smith IE (2003) Does timing of adjuvant chemotherapy for early breast cancer influence survival? J Clin Oncol 21: $3792-3797$

Sundararajan V, Hershman D, Grann VR, Jacobson JS, Neugut AI (2002) Variations in the use of chemotherapy for elderly patients with advanced ovarian cancer: a population-based study. J Clin Oncol 20: 173-178

Tingulstad S, Skjeldestad FE, Hagen B (2003) The effect of centralization of primary surgery on survival in ovarian cancer patients. Obstet Gynecol 102: $499-505$

Vernooij F, Heintz P, Witteveen E, van der Graaf Y (2007) The outcomes of ovarian cancer treatment are better when provided by gynecologic oncologists and in specialized hospitals: a systematic review. Gynecol Oncol 105: $801-812$

Warren JL, Harlan LC, Fahey A, Virnig BA, Freeman JL, Klabunde CN, Cooper GS, Knopf KB (2002) Utility of the SEER-Medicare data to identify chemotherapy use. Med Care 40, IV- 55-61

Warwick J, Kehoe S, Earl H, Luesley D, Redman C, Chan KK (1995) Longterm follow-up of patients with advanced ovarian cancer treated in randomised clinical trials. Br J Cancer 72: 1513-1517 